\title{
Observations of daytime activity in the nocturnal northern giant mouse lemur (Mirza zaza)
}

\author{
Daniel Hending $^{\mathrm{a}, \mathrm{b}, *}$, Heriniaina Randrianarison ${ }^{\mathrm{c}}$, Sam Cotton ${ }^{\mathrm{b}}$, \\ Marc Holderied $^{\mathrm{a}}$ and Grainne McCabe ${ }^{\mathrm{b}}$ \\ ${ }^{\text {a }}$ School of Biological Sciences, The University of Bristol, Bristol BS8 1TH, UK \\ ${ }^{\mathrm{b}}$ Bristol Zoological Society, Clifton, Bristol BS8 3HA, UK \\ ${ }^{\mathrm{c}}$ Mention: Zoologie et Biodiversité Animale, Université d'Antananarivo, BP 906 \\ Antananarivo (101), Madagascar \\ *Corresponding author's e-mail address: danhending2@gmail.com; \\ dan.hending@bristol.ac.uk
}

Received 4 May 2020; initial decision 11 June 2020; revised 11 November 2020; accepted 30 November 2020; published online 14 December 2020

\begin{abstract}
We provide an anecdote of daytime activity within the northern giant mouse lemur (Mirza zaza), a small threatened primate that has always been considered strictly nocturnal, in the Anabohazo forest of northwestern Madagascar. During the dry season, we witnessed two individual M. zaza travelling separately in the afternoon period of three different days. Our observations indicate that M. zaza may undertake activity that is essential for their survival within both the light and dark periods of a day-cycle, and our findings suggest that the activity cycle of this species may be highly flexible. These observations have important implications to understand the evolution of activity patterns in $M$. zaza, and these findings warrant future, long term studies to establish the annual activity patterns of $M . z a z a$ and to determine whether this species is potentially cathemeral and why.
\end{abstract}

\section{Keywords}

activity patterns, adaptive, daytime, flexible behaviour, Madagascar, Mirza zaza. 


\section{Observations}

Primate activity cycles have until recently always been considered to have a diurnal-nocturnal dichotomy, where species are active either during the daytime or night time portions of any 24-hour period (Curtis \& Rasmussen, 2006). However, many recent studies have demonstrated that primate activity cycles are highly adaptive and flexible, and the life histories of many species do not always strictly adhere to these diurnal or nocturnal activity cycles (Donati \& Borgognini-Tarli, 2006). Some primate species have now been observed to undertake foraging, travelling and social activity within both the light and dark periods of a 24-hour day cycle, and some primate species are now classified as cathemeral. Cathemerality is defined as behaviour in which an organism undertakes significant amounts of their activity at irregular and sporadic intervals within both the daytime and night-time periods of a day (Tattersall, 1987), and although many species have been observed to be active during both day and night, cathemeral activity is rare among primates in comparison to other mammals (Curtis \& Rasmussen, 2006; Bennie et al., 2014; Donati et al., 2016).

In the last 20 years, several studies have revealed the existence of flexible activity cycles and cathemerality within a range of primate taxa (Colquhoun, 2007), such as the owl monkeys (Aotus: Fernandez-Duque et al., 2008), and, most notably, in the lemurs of Madagascar (Donati et al., 2009). Cathemeral activity is now known to occur within several wild populations of lemur species, such as those of the Lemur (Donati et al., 2013), Eulemur (Donati et al., 2001, 2007; Schwitzer et al., 2007) and Hapalemur (Mutschler, 2002; Eppley et al., 2015) genera, and flexible activity cycles have also been observed in Avahi (Campera et al., 2019). It is not currently known how many primate species are cathemeral and details of activity cycles, and the proximate and ultimate factors that determine them, are still little-known for many species (Donati \& Borgognini-Tarli, 2006). However, a number of studies have been undertaken on lemurs and several hypotheses have been suggested to explain their flexible activity cycles and adaptive cathemerality, including predation avoidance strategies, dietary benefits, thermoregulatory benefits and competition avoidance (Donati et al., 2009). In this article we describe observations of daytime activity within the northern giant mouse lemur (Mirza zaza), a small Vulnerable primate endemic to northwestern Madagascar (Rode et al., 2013; Reuter \& Schwitzer, 2020). Mirza zaza, and the closely related M. coquereli, have been considered as 
strictly nocturnal based on previous studies of their behaviour, ecology and sociality (Pages, 1978; Kappeler, 1997; Markolf et al., 2008; Rode-Margono et al., 2016). Further, with the exception of some informal mentions of disturbance-induced arousal from sleep, there is no evidence of daytime activity for any of the other nocturnal cheirogaleid lemurs within the published literature. However, despite the significance of activity patterns for an understanding of a species' behavioural ecology (Kappeler \& Erkert, 2003), both Mirza remain understudied and their activity patterns are largely unknown.

Our observations took place during a capture-recapture experiment that we were conducting in the Anabohazo forest of the Sahamalaza-Iles Radama National Park, northwestern Madagascar (approximately $14^{\circ} 19^{\prime} \mathrm{S}, 47^{\circ} 54^{\prime} \mathrm{E}$ ) between March and August 2019. During our time at the study site, we spent 1-2 hours on average in the forest every day. Our observations of daytime activity in Mirza zaza took place in the month of July, which falls within the austral winter and the middle of Madagascar's dry season, when mean daily temperatures and precipitation rates are at their annual lowest (Mandl et al., 2018). We observed three instances of daytime activity in M. zaza involving two separate individuals, one female $(N=2$ observations) and one large male ( $N=1$ observation). We were able to identify the individual lemurs because the female had a rather unique (for this species) goldcoloured pelage and was part of a marked study population, whilst male $M$. $z a z a$ can be easily identified and distinguished by their large prominent testes (Rode-Margono et al., 2015). Our first observation of the female occurred at approximately 14:00 on 1 July 2019, where we witnessed her removing banana through the mesh of a deactivated Tomahawk live-trap before consuming it, and then travelling slowly within the surrounding trees for approximately 20 minutes before she finally moved out of sight. Two days later, we observed the same female active during daylight hours again, also at approximately 14:00. In this instance, we witnessed her moving slowly within the trees over a transect at a height of around $4 \mathrm{~m}$. Once she had become aware of our presence, she stopped moving and remained stationary on an exposed branch where we observed her resting for a period of 30 minutes before we moved on. We observed the male individual moving at a fast pace typical of Mirza (Rode-Margono et al., 2016) for a period of five minutes at approximately 13:00,05/07/2019, before we lost sight of the indi- 
vidual. We did not observe any vocal activity in either individual, and we did not observe any $M$. zaza active in daylight outside of July. Although we only observed daytime activity in M. zaza on three occasions (Figure 1), we frequently observed activity in this species at dusk and at night (we spent most of our time in the forest between 18:00 and 00:00).

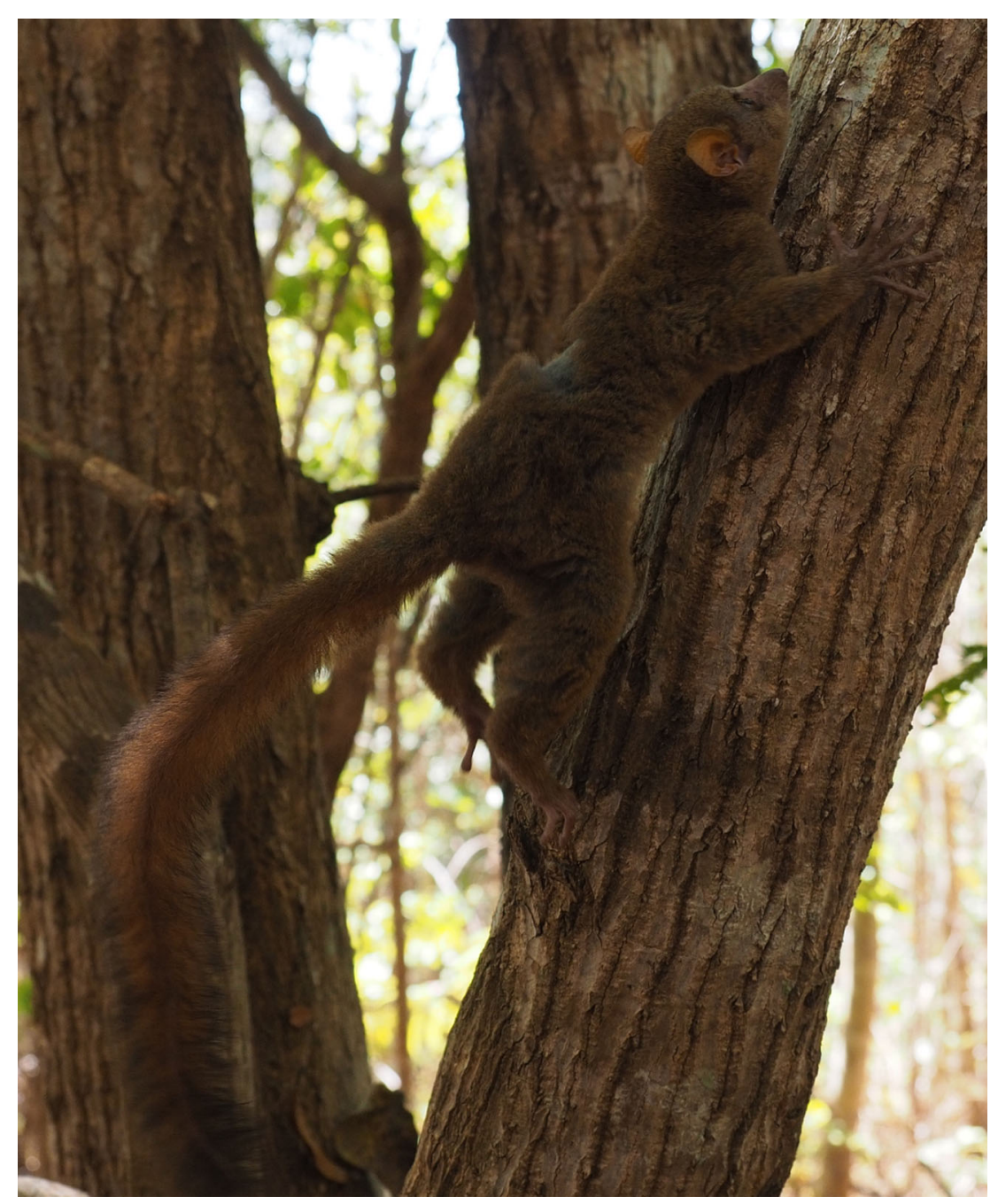

Figure 1. A northern giant mouse lemur (Mirza zaza) active during daylight hours in Anabohazo forest, Sahamalaza-Iles Radama National Park, northwestern Madagascar. Photo by Sam Cotton. 
Our observations indicate that Mirza may undertake periods of activity within both the light and dark periods of a day-cycle, but there are several possible proximate reasons that could have triggered our three observations. As one of our observations was of a female feeding on banana from a livetrap, it is possible that the smell of the banana within our traps may have aroused this individual from her diurnal sleep period during this time of low food availability at our study site (Wright, 1999); food presence can be a powerful driver of activity pattern change (Dishman et al., 2009) and Mirza have strong olfactory senses (Colquhoun, 2011). Our second observation of this female was also in the same area and at the same time as the first observation, perhaps because she was looking for the same food item in the trap. The female also remained stationary for 30 minutes during this observation, which would suggest that she was not at ease and perhaps not comfortable outside of her normal activity period. It is also possible that our observations were the result of accidental disturbance of sleeping sites. However, we do not believe this was the case for our observations, as three other nocturnal lemur species are abundant at this study site (Hending et al., 2017) and we never observed daytime activity in these three species. Another possible ultimate reason for our observations is that M. zaza may minimize predation risk via temporal crypticity (Curtis \& Rasmussen, 2006; Colquhoun, 2007; Tattersall, 2008), as they are small-bodied and therefore vulnerable to aerial and terrestrial predators (both diurnal and nocturnal) that are common within the National Park (Randriatahina \& Volampeno, 2012).

With the exception of a few published articles (Mirza coquereli: Kappeler, 1997; Markolf et al., 2008, M. zaza: Rode et al., 2013), the Mirza genus remains poorly known and there have been no systematic studies of their seasonal behavioural ecology and activity cycles (Rode-Margono et al., 2016). Our observations provide some evidence that $M$. zaza may undertake activity during both day and night periods and suggest that some nocturnal lemurs may not in fact be strictly nocturnal. However, it is possible for nocturnal animals to have brief activity bouts during daylight, and based on the cathemerality definition of Tattersall (1987) where an organism may be defined as cathemeral if "significant amounts of their activity, particularly feeding and/or travelling, occurs within both the light and dark portions of that cycle", our observations do not provide a definitive evidence of cathemerality in $M$. zaza. The finding of daytime activity in $M$. zaza, if confirmed, has important implications to understand the evolution of activity patterns in Mirza and other lemurs, and suggests that M. zaza may have the ability to 
be active during daylight, despite its nocturnal lineage (Santini et al., 2015). Adding M. zaza to the list of known cathemeral lemurs would imply that cathemerality evolved in lemurs far earlier than currently thought, and this supports the hypothesis that cathemerality developed early in lemur evolution (Tattersall, 2008). We therefore believe these valuable findings warrant future, long-term studies to establish the activity cycles of $M$. zaza, and to investigate whether this species may in fact be cathemeral, and if so, what type of cathemerality it can exhibit and why.

\section{Ethical note}

All research adhered to the policies of the participating institutions and the UK Home Office policies for work involving animals. All research adhered to the legal requirements of the UK and Madagascar. Research within the Sahamalaza-Iles Radama National Park was permitted by Madagascar National Parks, MNP (Permit number 245/19/MEEF/SG/DGF/DSAP/SCB. $\mathrm{Re})$. The Code of Best Practices for Field Primatology was consulted during the design of this study.

\section{Acknowledgements}

We thank National Geographic Society, La Vallée des Singes, Primate Conservation Incorporated, IdeaWild, Global Wildlife Conservation, Primate Society of Great Britain, University of Bristol and AEECL for kindly funding this research. We are grateful to MICET for their logistical support and Madagascar National Parks for granting us a research permit (245/19-MEEF/SG/DGF/DSAP/SCB.Re). Finally, we thank all of the field guides, cooks and porters that assisted us over the course of this research. $\mathrm{DH}, \mathrm{SC}, \mathrm{MH}$ and GM were responsible for study design and all fieldwork was conducted by DH and HR. All authors contributed to the preparation of the manuscript. This study was funded by National Geographic Society, La Vallée des Singes, Primate Conservation Incorporated, IdeaWild, Global Wildlife Conservation, Primate Society of Great Britain, University of Bristol and AEECL.

\section{References}

Bennie, J.J., Duffy, J.P., Inger, R. \& Gaston, K.J. (2014). Biogeography of time partitioning in mammals. — Proc. Natl. Acad. Sci. USA 111: 13727-13732. 
Campera, M., Balestri, M., Chimienti, M., Nijman, V., Nekaris, K.A.I. \& Donati, G. (2019). Temporal niche separation between the two ecologically similar nocturnal primates Avahi meridionalis and Lepilemur fleuretae. — Behav. Ecol. Sociobiol. 73: 55.

Colquhoun, I.C. (2007). Anti-predator strategies of cathemeral primates: dealing with predators of the day and the night. — In: Primate anti-predator strategies (Gursky, S.L. \& Nekaris, K.A.I., eds). Springer, Boston, MA, p. 146-172.

Colquhoun, I.C. (2011). A review and interspecific comparison of nocturnal and cathemeral strepsirhine primate olfactory behavioural ecology. — Int. J. Zool. 2011: 362976.

Curtis, D.J. \& Rasmussen, M.A. (2006). The evolution of cathemerality in primates and other mammals: a comparative and chronoecological approach. — Folia Primatol. 77: 178-193.

Dishman, D.L., Thomson, D.M. \& Karnovsky, N.J. (2009). Does simple feeding enrichment raise activity levels of captive ring-tailed lemurs (Lemur catta)? — Appl. Anim. Behav. Sci. 116: 88-95.

Donati, G., Baldi, N., Morelli, V., Ganzhorn, J.U. \& Borgognini-Tarli, S.M. (2009). Proximate and ultimate determinants of cathemeral activity in brown lemurs. - Anim. Behav. 77: 317-325.

Donati, G., Bollen, A., Borgognini-Tarli, S.M. \& Ganzhorn, J.U. (2007). Feeding over the 24-h cycle: dietary flexibility of cathemeral collared lemurs (Eulemur collaris). - Behav. Ecol. Sociobiol. 61: 1237-1251.

Donati, G. \& Borgognini-Tarli, S.M. (2006). Influence of abiotic factors on cathemeral activity: the case of Eulemur fulvus collaris in the littoral forest of Madagascar. - Folia Primatol. 77: 104-122.

Donati, G., Campera, M., Balestri, M., Serra, V., Barresi, M., Schwitzer, C., Curtis, D.J. \& Santini, L. (2016). Ecological and anthropogenic correlates of activity patterns in Eulemur. - Int. J. Primatol. 37: 29-46.

Donati, G., Lunardini, A., Kappeler, P.M. \& Borgognini-Tarli, S.M. (2001). Nocturnal activity in the cathemeral red-fronted lemur (Eulemur fulvus rufus), with observations during a lunar eclipse. - Am. J. Primatol. 53: 69-78.

Donati, G., Santini, L., Razafindramanana, J., Boitani, L. \& Borgognini-Tarli, S.M. (2013). (Un-) expected nocturnal activity in "Diurnal" Lemur catta supports cathemerality as one of the key adaptations of the lemurid radiation. - Am. J. Phys. Anthropol. 150: 99-106.

Eppley, T.M., Ganzhorn, J.U. \& Donati, G. (2015). Cathemerality in a small, folivorous primate: proximate control of diel activity in Hapalemur meridionalis. - Behav. Ecol. Sociobiol. 69: 991-1002.

Fernandez-Duque, E., Di Fiore, A. \& Carrillo-Bilbao, G. (2008). Behavior, ecology, and demography of Aotus vociferans in Yasuní National Park, Ecuador. - Int. J. Primatol. 29: 421-431.

Hending, D., McCabe, G. \& Holderied, M. (2017). Sleeping and ranging behavior of the Sambirano Mouse Lemur, Microcebus sambiranensis. — Int. J. Primatol. 38: 1072-1089.

Kappeler, P.M. (1997). Intrasexual selection in Mirza coquereli: evidence for scramble competition polygyny in a solitary primate. - Behav Ecol Sociobiol. 41: 115-127. 
Kappeler, P.M. \& Erkert, H.G. (2003). On the move around the clock: correlates and determinants of cathemeral activity in wild redfronted lemurs (Eulemur fulvus rufus). - Behav. Ecol. Sociobiol. 54: 359-369.

Mandl, I., Holderied, M. \& Schwitzer, C. (2018). The effects of climate seasonality on behavior and sleeping site choice in Sahamalaza sportive lemurs, Lepilemur sahamalaza. — Int. J. Primatol. 39: 1039-1067.

Markolf, M., Roos, C. \& Kappeler, P. (2008). Genetic and demographic consequences of a rapid reduction in population size in a solitary lemur (Mirza coquereli). - Open Conserv. Biol. J. 2: 21-29.

Mutschler, T. (2002). Alaotran gentle lemur: some aspects of its behavioral ecology. — Evol. Anthropol. 11(S1): 101-104.

Pages, E. (1978). Home range, behaviour and tactile communication in a nocturnal Malagasy lemur Microcebus coquereli. — In: Recent advances in primatology (Chivers, D.A. \& Joysey, K.A., eds). Academic Press, London, p. 171-177.

Randriatahina, G.H. \& Volampeno, N.S.M. (2012). Predation on two lemur species in Sahamalaza Peninsula, northwestern Madagascar. — In: Leaping ahead. Developments in primatology: progress and prospects (Masters, J., Gamba, M. \& Génin, F., eds). Springer, New York, NY, p. 105-110.

Reuter, K.E. \& Schwitzer, C. (2020). Mirza zaza. The IUCN Red List of Threatened Species 2020: e.T136684A120487592 (accessed 11 August 2020).

Rode, E.J., Nekaris, K.A.I., Markolf, M., Schliehe-Diecks, S., Seiler, M., Radespiel, U. \& Schwitzer, C. (2013). Social organisation of the northern giant mouse lemur Mirza zaza in Sahamalaza, north western Madagascar, inferred from nest group composition and genetic relatedness. - Contrib. Zool. 82: 71-83.

Rode-Margono, E.J., Nekaris, K.A.I., Kappeler, P.M. \& Schwitzer, C. (2015). The largest relative testis size among primates and aseasonal reproduction in a nocturnal lemur, Mirza zaza. - Am. J. Phys. Anthropol. 158: 165-169.

Rode-Margono, E.J., Schwitzer, C. \& Nekaris, K.A.I. (2016). Morphology, behaviour, ranging patterns and habitat use of the northern giant mouse lemur Mirza zaza in Sahamalaza, northwestern Madagascar. - In: The dwarf and mouse lemurs of Madagascar: biology, behavior and conservation biogeography of the Cheirogaleidae (Lehman, S., Radespiel, U. \& Zimmermann, E., eds). University Press, Cambridge, p. 235-254.

Santini, L., Rojas, D. \& Donati, G. (2015). Evolving through day and night: origin and diversification of activity pattern in modern primates. - Behav. Ecol. 26: 789-796.

Schwitzer, N., Kaumanns, W., Seitz, P.C. \& Schwitzer, C. (2007). Cathemeral activity patterns of the blue-eyed black lemur Eulemur macaco flavifrons in intact and degraded forest fragments. — Endangered Species Res. 3: 239-247.

Tattersall, I. (1987). Cathemeral activity in primates: a definition. — Folia Primatol. 49: 200202.

Tattersall, I. (2008). Avoiding commitment: cathemerality among primates. — Biol. Rhythm Res. 39: 213-228.

Wright, P.C. (1999). Lemur traits and Madagascar ecology: coping with an island environment. - Am. J. Phys. Anthropol. 110: 31-72. 